SISTEMA
ELETRONICO
DE REVISTAS
SER I UfPR

\title{
A influência do pensamento econômico na ideia de sustentabilidade e suas implicações para a percepção e conservação do mundo natural
}

\section{The influence of the economic thought on the idea of sustainability and its implications on the perception and conservation of the natural world}

\author{
Rodrigo Muniz da SILVA ${ }^{1^{*}}$ \\ ${ }^{1}$ Climate Change Impacts, Adaptation and Modelling (CCIAM), Center for Ecology, Evolution and Environmental Changes (cE3c), Faculdade \\ de Ciências, Universidade de Lisboa, Portugal. \\ *E-mail de contato: rodmunizs@gmail.com
}

Ensaio recebido em 13 de outubro de 2017, versão final aceita em 18 de junho de 2018.

\begin{abstract}
RESUMO: A sustentabilidade é um conceito cada vez mais arraigado nas sociedades, além de amplamente discutido no discurso acadêmico e na opinião pública, e a ideia de incorporá-lo foi assumida quase como um imperativo. Existe, nesse sentido, um claro reconhecimento de sua importância nas agendas social, econômica, ambiental, científica e política. Apesar disso, o conceito tornou-se uma expressão elusiva, com usos muito diversos, destituído de clareza na sua disseminação, prática e pesquisa, o que acabou dificultando seu entendimento. Com o alargamento dos problemas ambientais e a consequente preocupação emergida daí, a conservação do mundo natural passa a constituir centralidade na agenda da sustentabilidade. A despeito disso e da diversidade do conceito, sobretudo em uma conjuntura em que a economia é um dos maiores condicionantes dos padrões individuais e sociais em todo o mundo, a sustentabilidade foi paulatinamente reduzida ao seu viés econômico, tornando seu entendimento ainda mais limitado e, consequentemente, influenciando a conservação do mundo natural. Longe de buscar uma nova dimensão ou uma unificação conceitual para a sustentabilidade, esta proposta pretende explorar as ambiguidades e limitações das abordagens da sustentabilidade fraca e sustentabilidade forte, influenciadas - respectivamente - pela economia ambiental e pela economia ecológica, que caracterizam o viés econômico da sustentabilidade. Amparado por reflexões e análises filosóficas, este trabalho propõe um entendimento além do pensamento econômico, ancorando-se na ideia da "sustentabilidade absurdamente forte". O viés econômico da sustentabilidade será enfatizado na tentativa de demonstrar que a economia e os valores subjacentes a ela influenciam em grande medida os valores no entorno da sustentabilidade e nas relações entre o ser humano e a natureza. Inferiu-se que as relações humanas com a natureza são bastante condicionadas pela racionalidade econômica. Do mesmo modo, a sustentabilidade é
\end{abstract}


bastante influenciada por tal racionalidade, comprometendo o potencial papel transformador do conceito e as possibilidades de engendrar novas relações e valores.

Palavras-chave: sustentabilidade absurdamente forte; conservação; natureza; racionalidade; capital natural.

ABSTRACT: Sustainability is a concept increasingly embedded in societies, being widely discussed within the academic and public discourse, and the idea of incorporating it has been almost assumed as an imperative. In this sense, its importance in the social, economic, environmental, scientific, and political agendas is clearly recognized. Nevertheless, this concept has become an elusive expression, with diverse uses, and lacks clarity in its dissemination, practice, and research, which hinders its understanding. As the environmental problems and consequent concern that has emerged increase, the preservation of the natural world becomes central to the sustainability agenda. Despite this situation and the diversity of the concept, especially in a context in which economy is one of the major determinants of individual and social patterns around the world, sustainability has been gradually reduced to its economic bias, limiting its understanding even more and, consequently, influencing the conservation of the natural world. Rather than seeking a new dimension or a conceptual unification for sustainability, this proposal intends to explore the ambiguities and limitations of the approaches for weak sustainability and strong sustainability, influenced by the environmental economy and the ecological economy, respectively, which characterize the economic bias for sustainability. Based on philosophical reflections and analysis, this study proposes an understanding beyond the economic thought, anchoring in the idea of "absurdly strong sustainability". The economic bias for sustainability is emphasized attempting to demonstrate that economy and its values greatly influence the values regarding sustainability and the relationship between human being and Nature. It was inferred that human relationships with Nature are quite conditioned by economic rationality. Thus, sustainability is likewise strongly influenced by such rationality, compromising the potential transformative role of the concept and the possibilities of engendering new relationships and values.

Keywords: absurdly strong sustainability; nature; conservation; rationality; natural capital.

\section{Introdução}

O conceito de sustentabilidade, largamente discutido nos discursos acadêmicos e na opinião pública, está cada vez mais consolidado nas sociedades contemporâneas, considerando o esforço de incorporar sua ideia nos processos e estruturas da sociedade, quase como um imperativo. Existe, nesse sentido, um claro reconhecimento de sua importância nas agendas social, econômica, ambiental, científica e política (Becker, 2011). O conceito tornou-se uma palavra da moda, com usos muito diversos, diversidade tal que o termo pode não ser capaz de suportar. A diferença de definições, de usos e de âmbitos nos quais é referida leva a frequentes debates para alcançar sua melhor compreensão. É importante reconhecer que o termo ainda carece de aprimoramento e clareza, apesar de sua reconhecida importância e disseminação.

Com o alargamento dos problemas ambientais e a consequente preocupação com a preservação do mundo natural emergida daí, especialmente a partir da década de 1960, Fernandez (2011) aponta que foi impulsionada uma forte crítica aos modelos de desenvolvimento econômico vigentes até o momento. O Relatório do Clube de Roma, "Limits to Growth" (Meadows et al., 1972), representa um exemplo marcante, assinalando os limites dos ecos- 
sistemas para satisfazer as subjetividades humanas. A ideia de um ecodesenvolvimento (Sachs, 1993), que logo passou a ser identificado como desenvolvimento sustentável, teve seu início nestas conjunturas (Foladori \& Tommasino, 2000) que, por sua vez, apresentaram um papel bastante influente nas origens da economia ecológica (Fernandez, 2011).

Ao passo em que a degradação ambiental (destruição de ecossistemas e consequente perda de biodiversidade, poluição multifacetada e escasseamento das fontes naturais) começou a se tornar um problema para a humanidade, essas questões começaram a ser tratadas no âmbito das teorias econômicas (Fernandez, 2011). Tal como Becker (2011) coloca, a economia hoje é a maior força condicionante dos padrões individuais e sociais em todo o mundo, fruto da razão econômica. Tal racionalidade econômica, como aponta Leff (2004), é anti-natura, coisificando não apenas a natureza, mas toda forma de conhecimento no mundo na modernidade.

A economia é um estudo que encontra fundamentos na escassez de bens, na medida em que a busca por eles aumenta largamente sua quantidade disponível. De uma forma geral, algo é escasso quando se demanda mais desse algo em relação à sua disponibilidade. Nesse sentido, a escassez descreve uma relação entre as necessidades subjetivas e as possibilidades de serem estas subjetividades satisfeitas (Baumgärtner et al., 2006). Se assim entendido, a escassez acaba por descrever a relação humana com a natureza ${ }^{1}$ (Baumgärtner et al., 2006).

Esta ideia segue na esteira da definição de economia de Robbins (1932, p. 15), que a caracteriza como o "[...] estudo do comportamento humano enquanto uma relação entre os fins e os meios escassos que possuem usos alternativos"'2. Essa assunção fez com que se entendesse a economia como uma otimização sob constrangimentos, isto é, diante da escassez dos elementos (Baumgärtner et al., 2006). O reconhecimento da finitude dos elementos naturais diante de sua vasta necessidade para a espécie humana - em constante crescimento, assim como suas necessidades subjetivas - influencia a virada do projeto econômico para a natureza.

Cabe colocar que há diferentes abordagens econômicas, nas quais seu entendimento pode ser mais alargado - ou menos redutor - mas esta economia defendida por Robbins representa a corrente principal da economia, que exclui de certa maneira sua heterogeneidade, especialmente as abordagens mais heterodoxas.

Mas é a economia neoclássica, fundamentada na mecânica clássica, que explica o mundo única e exaustivamente através de sua quantificação (Fernandez, 2011) que veio influenciar o tratamento da natureza pela economia. A teoria econômica neoclássica argumenta que o livre mercado pode obter a melhor alocação de recursos através dos indivíduos que visam seus próprios e melhores interesses, sem a intervenção de regulação governamental (Beder, 2011). É através da teoria neoclássica que

\footnotetext{
${ }^{1}$ Quando se fala em Natureza seria necessário rebuscar sua acepção geral trabalhada ao longo da literatura e da história da filosofia. Quando se fala em ambiente, não se está a falar da Natureza, mas naquela Natureza-posta-em-perigo pelo agir humano desmedido (Soromenho-Marques, 1998). Contudo, de modo simplificado, a Natureza corresponde aqui à entidade sistêmica constituída de todos os seus processos físico-químicos, biológicos e geológicos, assumindo uma conotação semelhante, entretanto de forma geral mais abrangente, à de 'ambiente natural' e de 'mundo natural', correndo o risco de simplificar a ideia (tão complexa) de Natureza.

${ }^{2}$ Todas as traduções neste trabalho foram realizadas de forma livre pelo autor.
} 
a economia da natureza se estabelece (Spash 1999), tendendo a assumir o sistema econômico alheio aos constrangimentos e restrições ambientais, embora a poluição ambiental - por exemplo - possa ter sido tratada como uma externalidade há algum tempo. Contudo, as externalidades enquanto falhas de mercado, não eram consideradas tão significativas até então, apesar da defesa de Arthur Pigou pela intervenção governamental através de taxas e subsídios para que as externalidades fossem evitadas (Pearce, 2002). Não obstante, as externalidades negativas são centrais no argumento da economia ambiental, implicando na redução das relações entre humanos e natureza aos termos do livre mercado, das externalidades e da eficiência no uso dos chamados 'recursos naturais' (van den Bergh, 2000) ${ }^{3}$.

A forma com que a natureza é apreendida pela economia também foi lançada em outros moldes, buscando uma maior integração entre a economia e outras disciplinas diretamente relacionadas com os desafios ambientais, como é o caso da economia ecológica - distinta da economia ambiental - que busca um entendimento mais integrado na relação entre humanos e natureza, isto é, uma integração interdependente entre os sistemas sociais e ecológicos, mapeando a dinâmica entre ambos os processos (van den Bergh, 2000; Costanza, 1996). Já no final dos anos 1960 e início dos anos 1970, as leis da termodinâmica trouxeram consideráveis implicações para a teoria econômica (Spash, 1999). Nesta altura, o economista Georgescu-Roegen (1971) desenvolveu sérias críticas à economia neoclássica, apoiando-se nas leis da termodinâmica, sobretudo na ideia de entropia. Embora sem muito influenciar a economia ambiental da época, Georgescu-Roegen é provavelmente uma das mais importantes influências para a economia ecológica. A eficiência não é tão representativa para esta corrente, mas a justa alocação dos 'recursos' ambientais e o reconhecimento dos limites ecológicos são essenciais (Daly, 1992).

Apesar de mais sensível, a economia ecológica também expressa interesses bastante comuns à economia ambiental. No entanto, não é apenas pelos impactos adversos das atividades econômicas sobre o mundo natural não-humano e a dependência humana daquilo que a natureza oferece que a economia começou a seguir tal percurso, mas igualmente pelas novas oportunidades de negócio abertas pelo universo da conservação. Ademais, a tendência do perfil econômico nas políticas do ambiente também acaba por revelar a importância que se tem dado para a integração do valor econômico da natureza nas decisões políticas.

No novo debate da conservação, que se insere especialmente nas teorias econômicas e do negócio, as economias (ambiental e ecológica) se misturam $\mathrm{e}$ - assim - se requer um olhar sempre atento. Isso quer dizer que o olhar econômico visa a integração da natureza na economia com um propósito comum: quantificar. Quer seja tal quantificação em termos de perda para a sociedade em razão da 'escassez da natureza'; em benefícios providos (os chamados 'serviços ecossistêmicos'); em prejuízos providos ('desserviços ecossistêmicos'). Ambas as economias diluem-se no mesmo modelo de organização produtivo, o capitalismo, e ambas partilham de uma apropriação social da natureza, sem questionar severamente a racionalidade econômica neoclássica

\footnotetext{
${ }^{3}$ Os apóstrofos estão presentes em algumas expressões para discriminá-las, e/ou para chamar atenção do leitor quanto à sua conotação, tais como 'recursos naturais', 'capital natural' e 'serviços ecossistêmicos'.
} 
(Barkin et al., 2012). Esta racionalidade solidifica a relação puramente instrumental entre ser humano e natureza (Gorz, 1989), desagrega as pessoas da terra e a terra da natureza, permitindo a transação das chamadas mercadorias fictícias - nomeadamente: a terra, o dinheiro e o trabalho (Polanyi, 1957). Portanto, a excessiva racionalização da vida contemporânea, pós-industrialização, é essencialmente instrumental e econômica (Fernandes, 2008).

A relevância que se tem dado à economia no âmbito da sustentabilidade levou a um desequilíbrio junto às esferas sociais e ambientais, isso no contexto da teoria do triângulo da sustentabilidade (triple botton line). Isto é, a tese de que há em cada vértice do triângulo equilátero, três pilares: o social, o ambiental e o econômico. Entretanto, Becker (2011) afirma que esse pensamento tende a confundir as relações da sustentabilidade com as estruturas que as influenciam. $\mathrm{O}$ autor considera as esferas social e ambiental como relações de sustentabilidade, mas trata a economia como uma estrutura social e global específica que influencia as relações da sustentabilidade, tal como uma meta-estrutura ${ }^{4}$, isto é, que trata daquilo que atribui todo o contexto socioecológico.

$\mathrm{O}$ forte teor da economia voltada para a natureza traz implicações para como a perspectivamos, sua conservação e também as teorias de sustentabilidade que vão orientar as práticas humanas de maneira relativa aos sistemas socioecológicos que representam as interseções entre a 'cultura' e a 'natura'. É com frequência que a sustentabilidade é reduzida ao seu viés econômico, se o próprio sentido da economia já se encontra reduzido nas suas mais aceitas acepções, a sustentabilidade arrimada nesta redução tem seu entendimento ainda mais limitado. $\mathrm{O}$ viés econômico, nessa medida, caracteriza a sustentabilidade em duas vertentes: (I) sustentabilidade fraca e (II) sustentabilidade forte. A primeira é amparada pela economia ambiental, associada - como vimos - à tradição neoclássica, que aceita a substituibilidade entre o chamado 'capital natural' e o capital produzido pelo ser humano. A segunda é sustida pela economia ecológica, que argumenta que há limites nessa substituição.

Pretende-se, no presente trabalho, tecer algumas considerações sobre a incontornável ligação entre economia e a natureza, contextualizando o viés ambiental e ecológico da teoria econômica e sua influência na concepção das sustentabilidades fraca e forte, e caracterizando as assunções de ambas as sustentabilidades e suas implicações para a percepção e conservação do mundo natural. Amparado por reflexões e análises filosóficas, este trabalho propõe uma consideração sobre o entendimento da sustentabilidade, procurando demonstrar que a economia e os valores subjacentes a ela influenciam em grande medida a percepção que se tem do mundo natural e as abordagens para a sua conservação.

\section{Sustentabilidade}

A discussão sobre a sustentabilidade alargou-se e difundiu-se enormemente nos seus quase trinta anos de existência. O conceito, apropriado

\footnotetext{
4 “Becker (2011) introduz em sua obra o conceito de 'metaestruturas', e as define como a evolução histórica das estruturas condicionantes dos ensinamentos e ações, instituições e relações, compostas por quatro elementos: (1) assunções básicas (basic assumptions), (2) avaliações básicas (basic evaluations), (3) forças motrizes (driving forces), (4) institucionalizações (institutionalizations). A ciência, a tecnologia (entre outras) também são consideradas metaestruturas" (Muniz, 2013, p. 16).
} 
globalmente, é discutido tanto no âmbito acadêmico quanto na esfera pública, além de ter evoluído constantemente, permitindo que neste ínterim pudessem ser defendidas e impulsionadas diversas correntes teóricas que, entretanto, de forma isolada, procuraram desenhá-la e incorporá-la conforme suas conjunturas.

Há muito que possa ser referido sobre a sustentabilidade, desde seus primeiros aspectos conceptuais às mais divergentes práticas que a (des) caracterizam $^{5}$, desde seu mais consentido reconhecimento às mais veementes críticas. Os conceitos e as práticas da sustentabilidade divergem a tal ponto que ao mesmo tempo em que se caracteriza a sustentabilidade enquanto campo muito difuso, descaracteriza qualquer sentido razoável que ela possa vir a ter.

O uso moderno da palavra sustentabilidade teve sua origem formal estabelecida a partir do 'Relatório de Brundtland' (também conhecido como 'Nosso Futuro Comum'). Reconhece-se que o conceito tem origens mais antigas, como esclarecem Foladori \& Tommasino (2000), originando-se da ideia de ecodesenvolvimento (Sachs, 1993). A sustentabilidade corresponde frequentemente à expressão 'desenvolvimento sustentável', propondo a noção de um "desenvolvimento que satisfaz as necessidades do presente sem comprometer a capacidade de as gerações futuras satisfazerem as suas próprias necessidades" (WCED, 1987, p. 8). O Relatório de Brundtland (WCED, 1987, p. 8) afirma uma "[...] nova era de crescimento econômico [...]", assumindo tal crescimento, como "[...] absolutamente necessário [...]" para que a pobreza - principal responsável, no entender do relatório, pelo desgaste do ambiente - seja mitigada.

O desenvolvimento sustentável propõe uma versão de desenvolvimento (econômico) supostamente compatível com a preservação do ambiente natural. Contudo, é indiscutível o centramento no ser humano, afora algumas passagens específicas sobre a responsabilidade para com a biodiversidade selvagem, porém muito ainda ligado ao seu potencial utilitário econômico, deixando bem claro que é o bem-estar humano a razão para a preservação da natureza (Holland, 2003).

Em contrapartida, é indiscutível que há certo componente moral e prudencial nas suas linhas. Assume, por exemplo, que a pobreza é um mal em si e deve ser erradicada, entretanto o relatório falha ao não reconhecer a significância da desigualdade tanto para a pobreza quanto para a problemática ambiental. Nesse sentido, uma importante linha de argumento é a forte ligação entre a equidade intrageracional e intergeracional, mas muito embora assim seja, seus pressupostos exibem com clareza que o desenvolvimento sustentável, na ótica de Brundtland (WCED, 1987), é um desenvolvimento que sustenta o progresso (econômico) humano no futuro (Holland, 2003).

A expressão desenvolvimento sustentável abriga, todavia, certa ambiguidade, qual um paradoxo, que Shiva (1992) bem argumenta: o crescimento e desenvolvimento (tidos como criaturas do mercado) a promover a cura para a crise desencadeada por eles próprios. O termo sustentabilidade adentrou na teo-

\footnotetext{
${ }^{5}$ Existem caracterizações tão diversas que se opõem umas às outras; dentro de algumas vertentes de pensamento econômico da sustentabilidade é possível distinguir correntes bem diferentes. O exacerbado crescimento econômico nem sequer pode ser caracterizado como sustentável, ainda que o seja corriqueiramente.
} 
ria econômica em um momento em que desenvolvimento era sinônimo de crescimento econômico. $\mathrm{O}$ desenvolvimento assim entendido é insustentável, pois enfraquece o sistema ecológico e acaba por destruir os meios de sustento da população humana, especialmente os mais fragilizados e vulneráveis. Assim, aumentando a pobreza, as desigualdades e as injustiças ao invés de reduzi-las.

Shiva (1992, p. 187) alega que o "[...] 'crescimento com equidade' e o 'crescimento com sustentabilidade' [acabam por ser] tentativas de legitimar e perpetuar um crescimento econômico em um período de dúvida". A economia de mercado, segundo a autora, influencia em grande medida as estratégias de desenvolvimento, essas - por sua vez - resultam na destruição de outras formas de economia, como a dos processos ecológicos e da sobrevivência da população humana mais fragilizada. A negligência desses processos revela que o desenvolvimento é uma ameaça à integridade ecológica bem como à sobrevivência humana, cujas fragilidades são representadas apenas enquanto externalidades negativas resultantes do processo de desenvolvimento, portanto, reduzidas a produtos da economia de mercado e do capital produzido pelo ser humano, que representam os principais árbitros institucionais na modernidade.

Anteriormente às concepções modernas da economia, a humanidade sustinha-se diretamente do ambiente natural, com uma conexão mais direta com a Natureza, sustentando-se através dela e sustentando-a em sua integralidade (Shiva, 1992). O sistema natural, dantes considerado uma essência comum, nas mãos da economia moderna e do mercado é um recurso passível à exploração humana para o acúmulo de capital, levando inexoravelmente à escassez da economia da natureza, da sobrevivência e da sustentabilidade. O desenvolvimento sustentável preserva, segundo Shiva (1992, p. 189), a assunção equivocada de que a economia definida pelo capital e pelo mercado é mais essencial para o bem estar humano que a economia da natureza e a economia da sobrevivência, sendo assim, a "natureza encolhe na medida em que o capital cresce".

Ao passo em que o desenvolvimento sustentável é oferecido para a solução da problemática ambiental resultante do crescimento econômico, perde-se o real significado de sustentabilidade (Shiva, 1992). A concepção moderna de sustentabilidade deve reconhecer que a natureza é o arrimo fundamental para a vida humana e não-humana, e as implicações do conceito de sustentabilidade passam pela proteção da integridade da natureza e de seus processos, ainda que se queira preservar a boa vida humana.

Atendendo à noção de que o desenvolvimento tem sido compreendido e estabelecido à luz do crescimento econômico, o desenvolvimento sustentável não deve ser diretamente identificável com a sustentabilidade, isto é, são expressões distintas (Dower, 2003). A sustentabilidade deve extrapolar a economia moderna e atender uma amplitude que corresponda à vida boa ${ }^{6}$ humana, considerando as relações que a espécie humana expressa com ela própria - seja em relação às gerações futuras, presentes ou passadas -, com outras espécies e com a

\footnotetext{
${ }^{6}$ 'Vida boa' aqui se refere aos conceitos de Aristóteles, como apontam Bina \& Vaz (2011, p. 13): "One strand of the modern revival of virtue ethics has to do with reconstructing the eudaimonia concept for contemporary purposes: eudaimonia is an ancient Greek concept and central of Aristotle's philosophy. It meant the highest human good and therefore the main objective of life and of politics. It has been translated as good life or human flourishing or happiness".
} 
Natureza em geral (Muniz, 2013). Assim, é preciso ter cuidado e clareza com a forma com que é usada a expressão sustentabilidade, pois pode ser expressada de maneiras diversas, mesmo antagônicas.

Embora pressuponha um valor, a sustentabilidade não representa um valor em si, o que permite assumir que não representa uma coisa boa nem ruim. Mas ainda assim é vista na sociedade como algo positivo, independentemente das práticas e ideologias que subjazem ao conceito. Portanto, antes de tudo, o que se deve questionar é: o que deve ser sustentado? Para quem deve ser sustentado? Por quais razões? De que modo? (Redclift, 1987; Jamieson, 1998; O’Neill et al., 2008; Becker, 2011).

O significado literal da sustentabilidade relaciona-se à capacidade de manter algo através do tempo e de sua existência, isto é, uma ideia de continuidade (Simpson \& Weiner, 1989). Qualquer sistema é passível de ser sustentado, pode ser um sistema - natural, como um ecossistema, ou social, como um sistema econômico -, pode ser uma entidade (como um ser vivo ou capital) ou até mesmo um processo (como é a evolução), seja pela ação humana ou pelos próprios sistemas.

Afora continuidade, que não representa em si um valor, reconhecem-se, segundo Becker (2011), outras dimensões da sustentabilidade, nomeadamente: o caráter orientador (normativo e avaliativo) e o caráter relacional (a ver com as relações dos seres humanos entre si, ambiente natural e outras espécies). A sustentabilidade é orientadora enquanto é considerada guia fundamental para as ações, decisões e interações na comunidade global para o delineamento do futuro comum da humanidade, afirmada pelas agendas políticas internacionais. A sustentabilidade é relacional pois expressa-se através de três constituintes relacionais funda- mentais: (I) relação dos seres humanos com seus contemporâneos; (II) relação dos seres humanos com as gerações futuras; (III) relação entre os seres humanos e a natureza. Isso permite vislumbrar que, inerente à sustentabilidade, há uma componente ético-filosófica fundamental (Becker, 2011).

É imprescindível que haja uma interação entre essas características da sustentabilidade, isto é, entre a continuidade, orientação e relação. Se assim vislumbrada, a sustentabilidade permite ampliar a cadeia das relações humanas, contemplar as gerações futuras e atravessar as fronteiras da espécie humana. A sustentabilidade, permite - de tal modo - refletir sobre quais responsabilidades, obrigações e deveres os seres humanos possuem, e indicar como agir diante de si e da natureza nessa complexa cadeia relacional (Becker, 2011; Muniz, 2013).

Longe de buscar uma nova dimensão ou uma unificação conceitual para a sustentabilidade, a diversidade e complexidade do conceito nos leva a chamar a atenção sobre a forma com que este é empregado. Isto pois a pouca atenção e a pouca reflexão sobre seu conceito resulta na, e revela a, insuficiência das práticas para a sustentabilidade, corroborando o vazio conceitual atribuído ao seu conceito e, igualmente, às suas relações.

\section{O viés econômico da sustentabilidade}

A sustentabilidade trespassa todo o conhecimento sobre a vida humana e seus processos de convivência e, por isso, atravessa os diversos setores da sociedade. Quando arrolada através do viés econômico, se expressa sobretudo através de dois sentidos: sustentabilidade fraca e sustentabilidade forte. 
Considerando, primeiramente, a sustentabilidade fraca, pode-se dizer que ela aceita a 'susbstitutabilidade' (substitutability) entre o 'capital natural' pelo capital produzido pelo ser humano. Enquanto que, a sustentabilidade forte advoga que há limitações para sua aceitação. Estas perspectivas serão abordadas a seguir. Em seguida, será abordada a perspectiva que confronta a perspectivação da natureza enquanto capital natural: a sustentabilidade 'absurdamente forte' de Alan Holland (1997). Contudo, inicialmente serão abordados alguns pressupostos conceituais sobre a substituibilidade que marca a alegada diferença existente entre as perspectivas econômicas referentes à sustentabilidade.

\subsection{Substituibilidade}

Constata-se que houve uma relativa preocupação da economia com o ambiente natural e sua resposta é a tentativa de computá-lo em termos econômicos, bem como os impactos que sobre ele recaem. Até então, a forma mais consentida é a de encarar o mundo natural enquanto capital. Embora bem distintas, tanto a economia ambiental quanto a ecológica, ambas tendem a valorar economicamente a natureza, conduzindo-a a um estatuto de capital natural.

Consequentemente, a abordagem econômica sobre a problemática ambiental ainda cria, apesar da perspectiva diferenciada da economia ecológica, certo desconforto entre alguns ambientalistas.
Primeiramente, assumir a natureza como um capital pode conduzir a uma má representação ${ }^{7}$ do comportamento humano relativamente à natureza e, por conseguinte, trai sua própria natureza e a própria natureza. Nesta medida, o ser humano é entendido como um aglomerado de preferências a serem satisfeitas e maximizadas a partir da natureza, sendo esta considerada um aglomerado de recursos para satisfação humana - o que constitui o valor econômico.

Deste modo, o ser humano e a natureza são homogeneizados e grosseiramente simplificados. Em segundo lugar, a valoração econômica pode refletir a arrogância humana, negligenciando os interesses e as preferências das entidades não-humanas, demonstrando a disposição humana a sobrevalorizar seus mais supérfluos interesses em detrimento das mais legítimas reivindicações não-humanas. Não obstante, a maior arrogância é a crença de que o mundo limita-se e identifica-se ao mundo humano, desconsiderando o mundo natural (Holland, 1997).

Uma vez que os impactos econômicos no ambiente natural podem ser mensurados economicamente, segundo a perspectiva econômica, vem à tona também a possibilidade de compensar tais impactos gerados. É aqui que a substituibilidade começa a se fazer notar na suposição de que o 'capital natural' pode ser substituído pelo capital produzido pelo ser humano e compensar quaisquer danos para a natureza. É importante salientar algumas diferenças entre o capital produzido pelo ser humano e do capital natural.

\footnotetext{
${ }^{7} \mathrm{O}^{\prime}$ Neill (1997) refere essa assunção como uma traição ao comprometimento humano em relação à Natureza e à natureza do ser humano. Holland faz referência a esse tipo de traição. Entretanto, equipara tal traição a uma má representação do ser humano na sua relação com a Natureza, como sugere a passagem: "The betrayal is of two kinds. One is a betrayal (mostly, a misrepresentation) of the human response to nature, and therefore a betrayal of human nature. The second is a betrayal (again, mostly, a misrepresentation) of nature itself" (Holland, 1997, p. 120).
} 
O capital produzido pelo ser humano compreende todos os artefatos em geral e também o capital humano e social, isto é, as pessoas, suas competências, inteligência, virtude, entre outros (Holland, 2003). O capital natural compreende os chamados 'recursos' renováveis e não renováveis produzidos e mantidos pelos processos naturais (como o petróleo, minerais, plantas e animais, reservas hídricas) que são extraídos dos ecossistemas, bem como os chamados 'serviços ecossistêmicos' (Gómez-Bagethum et al., 2010) que fazem a manutenção climática, que mantém a qualidade e a operacionalidade dos processos da biosfera (atmosfera, solo e ciclos hidrológicos etc), incluindo o controle das reservas de água para consumo, a assimilação de resíduos, a regeneração do solo, a polinização das plantações, a provisão de alimento - incluindo os advindos dos oceanos - e a vasta informação genética (Berkes \& Folke, 1994). Portanto, o capital natural tem a ver não apenas com os aspectos físicos naturais, mas com a informação genética, com a biodiversidade, com os sistemas de suporte de vida e sumidouros (Holland, 2003).

Essa caracterização do capital natural é firmemente baseada no grau de interesse humano. Os 'recursos' não renováveis acabam por ser considerados 'capital natural' apenas se extraídos dos ecossistemas. Embora não haja clareza na definição de Berkes \& Folke (1994) de que para ser capital natural precisa ser extraído da natureza (ou de que o material em si na natureza conta como capital natural), fica implícito - quase explícito - que o que faz a água ser consumível é o fato de ser consumível por seres humanos e do mesmo modo quando se considera a deterioração da qualidade atmosférica, é relativamente à representação dessa qualidade para o uso humano. Isto é, uma das problemáticas que se assentam no conceito de 'capital natural' é a ideia implícita de que para ser capital requer uso e transformação pelo ser humano, o que dificulta assinalar a diferença entre 'capital natural' e capital produzido pelo ser humano (Jamieson, 1998).

Em última instância, todo capital produzido pelo ser humano advém da natureza e consequentemente se poderia dizer, ao extremo, que não há capital produzido pelo ser humano. Entretanto, a questão que se levanta é se haverá a possibilidade de se converter tudo que é natural em capital produzido pelo ser humano, ou seja, será possível sustentar a vida humana apenas alicerçada na sua produção? (Holland, 1997). Obviamente, não.

Solow (1974) argumenta, em um contexto hipotético, que o mundo poderia sustentar-se sem os "recursos naturais" ${ }^{8}$, implicando em substituições entre capital produzido pelo ser humano e 'capital natural', isto é, nos recursos utilizados. Holland (1997) nota que é preciso observar e analisar as ambiguidades em alguns critérios ou condições para a ocorrência da substituição entre capital produzido pelo ser humano e 'capital natural', nomeadamente: I) o propósito; II) o grau de eficácia; e III) a ideia que se tem de 'capital natural' e capital produzido pelo ser humano.

Primeiramente, é preciso considerar sob qual pretexto se deve dar a substituição, ou seja, qual o seu propósito. $\mathrm{O}$ argumento de que os elementos podem ser substituíveis ou substitutos, requer primeiro que se analise o que se quer manter depois de

${ }^{8}$ Holland (1997, p. 121) explica que se deve considerar dois aspectos fundamentais nas assunções de Solow: 1) se dão em um contexto hipotético; 2) quando Solow se refere a 'recursos naturais' ele está se referindo apenas aos não renováveis. 
substituído o elemento. O capital humano é substituível pelo capital natural na medida em que "[...] preserva o grau e o tipo de benefícios dos quais os seres humanos obtêm do capital natural" (Holland, 1997, p. 122). Essa assunção não parece gerar, a princípio, conflitos no assunto da substituibilidade e, consequentemente, entre as sustentabilidades forte e fraca. Entretanto, quando se pretende averiguar a substituição do 'capital natural', os conflitos são mais intrincados. Visto de uma forma simples, ao destruir uma floresta tropical com espécies endêmicas, tendo em vista a extração de madeira, com o que se pretende substituir a mata ali presente? (I) Por árvores artificiais; (II) por quaisquer árvores que poderão suprir o interesse humano pela madeira; (III) por árvores nativas, entretanto, não endêmicas; (IV) pelas mesmas árvores nativas e endêmicas exploradas. Nesse sentido, se um 'capital natural' particular é substituível pelo capital humano, “[...] pode depender inteiramente do grau de precisão que é demandado na especificação do propósito" (Holland, 1997, p. 123).

Quando se considera um elemento substituto, não se supõe, primariamente, que tenha todas as propriedades do elemento a ser substituído. Se assim fosse, os conflitos seriam mais brandos. O que se vislumbra, geralmente, é se um substituto é suficiente para o propósito, mas mesmo que haja acordo sobre o propósito, quão bom deve ser o substituto para que seja suficiente? (Holland, 1997). Segundo este autor, são as circunstâncias e o grau de tolerância à substituibilidade que determinarão as respostas. Bastaria que fossem quaisquer árvores para repovoar a mata destruída ilustrada acima?
O fato de a substituição ter implicado intervenção humana, mesmo que seja a substituição pela mata nativa endêmica, pressupõe-se uma substituição por capital humano? As árvores cultivadas ${ }^{9}$ pelos seres humanos devem ser entendidas enquanto 'capital natural' ou capital produzido pelo ser humano? Holland (1997) sugere que sejam ignoradas as respostas mais extremas, pois pode-se analisar pouco delas. Ora, se assumir como capital produzido pelo ser humano tudo aquilo que for afetado por quaisquer das suas intervenções, é possível que até alguns pressupostos conservacionistas possam ser questionados, como é o repovoamento de matas nativas com espécies endógenas. Por outro lado, se assumir enquanto natural qualquer coisa que tenha sido feita a partir de elementos naturais, todo capital humano não seria humano, mas sim natural.

Holland (1997) recorre à distinção entre 'matéria' e 'forma', presente na obra de Aristóteles. Matéria e forma aplicam-se tanto a elementos viventes quanto aos não viventes. De acordo com Aristóteles, tudo pode ser analisado a partir da forma (isto é, aquilo que é) e da matéria (ou seja, daquilo que é feito). Se aplicado esse critério aos elementos vivos, um mundo cultivado pelas mãos humanas se encontraria, talvez, entre o mundo humano e o mundo natural. Um gato domesticado preserva suficientemente sua forma natural enquanto mantém características que lhe permitirão viver uma vida selvagem. O que dizer do montado português que, na medida em que para manter-se tal como é, requer constante, permanente e necessária intervenção humana? Embora seja um (agro)ecossistema, suas peculiaridades fazem deste um capital humano? Ao

\footnotetext{
${ }^{9}$ Holland (1999, p. 63) também se refere ao "capital natural produzido pelo homem" como capital cultivado (cultivated captial), também chamado por outros autores de biodiversidade econômica e social (de modo grosseiro, todas as plantas cultivadas e animais domesticados).
} 
passo que a sustentação do montado objetiva a exploração da cortiça, e não o valor do ecossistema em si (ou valor intrínseco), ele é vislumbrado enquanto um capital natural ou humano? E mesmo que fosse preservado pelo seu valor intrínseco, que tipo de capital seria? Existe uma série de discussões que não caberá discutir com maior profundidade aqui, mas são elementos que precisam ser considerados nas assunções da sustentabilidade, sobretudo no que diz respeito à transformação da natureza em capital, seja ele natural ou produzido pelo ser humano, o que será discutido adiante.

\subsection{Sustentabilidade fraca}

O debate acerca da sustentabilidade, a partir do viés econômico, acaba por ser bem caracterizado pela distribuição dos bens ao longo do tempo para o bem estar das futuras gerações (O’Neill et al., 2008). Mesmo o viés econômico da sustentabilidade deveria ultrapassar a justa distribuição de bens entre as gerações humanas, visando alcançar a justiça ecológica ${ }^{10}$ (Baxter, 2005) através do tempo, bem como um novo entendimento do ser humano econômico (Becker, 2006; Murtaza, 2010; Bina \& Vaz, 2011). Mas é a distinção entre as duas formas de capital (produzido pelo ser humano e natural) que acaba por determinar as vias para a sustentabilidade a partir da perspectiva econômica. Estas vias são a sustentabilidade fraca e a sustentabilidade forte.
O que as distingue fundamentalmente é o tipo de capital que se pretende sustentar para o futuro, e até que ponto devem ser substituíveis o capital produzido pelo humano e o capital natural, tendo que a substituição é uma questão complexa sem uma resposta determinista e definitiva. Deste modo, fica claro o imperativo da racionalidade instrumental e econômica, na percepção da sustentabilidade.

A chamada sustentabilidade fraca é caracterizada pela sustentação, sem declínio, do capital total, compreendendo tanto 'capital natural' quanto capital produzido pelo ser humano (Pearce et al., 1989). Essa versão da sustentabilidade está claramente associada à tradição neoclássica e, por isso, à economia ambiental. Isto porque defende que o que importa, sobretudo, é o bem estar humano não estar em declínio através do tempo (Pearce, 1994). Se assim, desde que o bem estar humano seja assegurado, à primeira vista, segundo Jacobs (1995), a sustentabilidade fraca advoga que o capital produzido pelo ser humano e o 'capital natural' são infinitamente substituíveis, na esteira de Solow (1974), que argumenta semelhantemente. Beckerman (1994) afirma que, desde que estejam tais capitais em equilíbrio, não haverá declínio no bem estar humano. A convicção dos economistas ambientais na substituibilidade da natureza justifica quaisquer esforços para sua valoração econômica, sem que com isso se assegure - necessariamente a manutenção da biodiversidade e da natureza em geral (Ehrenfeld, 1988) ${ }^{11}$.

\footnotetext{
${ }^{10}$ A justiça ecológica, com fortes influências da ética ambiental, argumenta pela obrigação moral da espécie humana em respeito às outras espécies. As atividades humanas continuam a ameaçar a existência da biodiversidade, colocando em causa as condições de vida também da humanidade (Baxter, 2005).

${ }^{11}$ Ehrenfeld (1988), afirma que um estudo demonstrou que "it was economically preferable to kill every blue whale left in the oceans as fast as possible and reinvest the profits in growth industries rather than to wait for the species to recover to the point where it could sustain an annual catch".
} 
Importa realçar que apesar da defesa específica pelo bem estar humano em detrimento da preservação do estado atual de 'capital natural', constata-se que mesmo na sustentabilidade fraca há limites para a substituibilidade,. Isto é, a substituição não é sugerida incondicional e infinitamente, pois é sabida a dependência da boa qualidade ambiental para o bem estar e sobrevivência humana (O'Neill et al., 2008).

Contudo, isto não isenta a sustentabilidade fraca de alguns pontos críticos. Inicialmente, as referências aos bens ambientais sobre esta perspectiva, assim como vislumbrado na economia ambiental, são limitadas aos aspectos estritamente econômicos, associados à teoria neoclássica. A destruição das florestas, bem como a extinção de espécies, poderia ser legitimada de alguma maneira, desde que o bem estar humano não entrasse em declínio e desde que houvesse substitutos viáveis para a biodiversidade com utilidade para a espécie humana (Jamieson, 1998).

Está claro que a segurança da humanidade depende da proteção da biodiversidade e o curto prazo, a eficiência e o interesse próprio priorizados por esta perspectiva levam, invariavelmente, ao comprometimento do estado do mundo natural. Tietenberg (1992) prevê que é possível alcançar um estado estacionário mas com um possível crescimento econômico a ser reduzido gradualmente, com uma gestão adequada, levando as gerações presentes e futuras a um estado equilibrado, de sustentabilidade, o que ele chama de gestão da transição para a sustentabilidade (managing the transition).

Contudo, nesta abordagem aliada aos pressupostos do crescimento econômico, com o rápido desgaste do ambiente natural para garantir não somente as necessidades, mas as extravagâncias humanas, acrescentando-se o excessivo crescimento populacional, são elevados os riscos da depleção irreversível do ambiente, tendo como referência a sobrevivência humana. Isto é, a humanidade pode nunca ser capaz de alcançar tal estado estacionário proposto pela gestão de Tietenberg (1992), antes do seu desfalecimento.

A perspectiva de Tietenberg revela que a maioria das pessoas estaria mais disposta a assumir uma transição mais lenta para o estado estacionário, sem que o bem estar e a qualidade de vida tivessem que ser reduzidos. Tietenberg (1992) parece acreditar que poderá existir concomitantemente um crescimento econômico. Contudo, objetivar a sustentabilidade através do bem estar em detrimento das fontes naturais manifesta pontos críticos relevantes.

Primeiramente levanta-se a questão: bem estar para quem? Para toda a espécie humana? Ou apenas para os mais favorecidos? De acordo com a economia ambiental, que influencia em grande medida a versão fraca da sustentabilidade, não parece haver implicações de justiça intrageracionais. Enquanto as populações mais abastadas se privilegiassem, tendo pouco reduzido seu bem estar, em que ponto estariam as populações humanas mais frágeis e vulneráveis? Talvez com menos ainda do que possuem, considerando que o crescimento econômico gera ainda mais iniquidades e injustiças, e por dependerem ainda mais intensamente das fontes naturais para sua sobrevivência.

Sob este ponto de vista, a eficiência manifesta grande influência, pois o agregado de bem estar acaba sobrepujando as considerações sobre a justiça e a equidade. Existe uma assimetria entre as justiças intra e intergeracionais, em que são sutis as extrapolações. Nesse sentido, outra questão que é colocada é sobre a mensuração do bem estar e 
sua extrapolação através do tempo. A mudança das circunstâncias pode ser suficiente para que a teoria do bem estar seja inapropriada (Holland, 1999). Como estabelecer comparações entre o bem estar através de populações tão distintas? Se no seio das nações, sobretudo nos países em desenvolvimento, as injustiças são tão marcadas, traçando diferentes noções do bem estar e da qualidade de vida, as dificuldades de se avaliar acentuam-se entre as nações. Quando se intenta extrapolar as discussões sobre o bem estar às gerações futuras, os desafios são ainda mais intrincados. Holland (1999) argumenta que o bem estar atual -bem como a felicidade, por exemplo - é uma função de numerosas circunstâncias que não podem, de modo realístico, ser antecipadas e promovidas. Também é importante realçar que os interesses de bem estar e satisfação são condicionados pelo contexto econômico, social e político e das instituições que prevalecem no tempo (Holland, 1999).

Daly (1995) complementa, argumentando que o bem estar das futuras gerações está além do controle e dos propósitos da atual geração, pois segundo ele não há garantias nem obrigações em relação ao bem estar das gerações futuras, mas com a capacidade de tais gerações de produzir, a partir de um mínimo de 'capital natural'. Segundo o argumento de Daly, não há controle sobre o bem estar, mas sim sobre os 'recursos' e daí a importância, no seu entender, de sustentar o 'capital natural', ideia que suporta a sustentabilidade forte. Porém, a versão forte da sustentabilidade, embora seja mais alinhada aos pressupostos ambientalistas, também apresenta lacunas (Jamieson, 1998), como será considerado adiante.

\subsection{Sustentabilidade forte}

Ao passo em que a sustentabilidade fraca afirma que o que importa ser sustentado é a soma entre os capitais, desde que o bem estar humano não decline, a sustentabilidade forte advoga que o que não deve sofrer declínio é o 'capital natural' (Pearce et al., 1989; Beckerman, 1994; Jamieson, 1998; O’Neill et al., 2008). Os proponentes desta corrente da sustentabilidade são os mesmos simpáticos e defensores da economia ecológica, compartilhando o pressuposto principal de que há limites para que o 'capital natural' seja substituído pelo capital produzido pelo ser humano.

Nesse sentido, a sustentabilidade requer que sejam mantidos as fontes naturais acima de um nível julgado crítico (O’Neill et al., 2008). Os proponentes da sustentabilidade forte, assim como os da sustentabilidade fraca, também objetivam o mantenimento da capacidade humana de gerar bem estar. No entanto, defendem que para manter essa capacidade é necessário que o 'capital natural' também não decline, na medida em que o bem estar humano depende da boa sustentação das fontes naturais (Holland, 1999). Van den Bergh (2007) afirma ainda que o objetivo na versão forte da sustentabilidade é que os capitais sejam sustentados separadamente. Uma das razões para tal, é a afirmação de Daly (1995) de que o capital produzido pelo ser humano e o capital natural são antes complementares, não substitutos. O primeiro ponto que sustenta essa afirmação de Daly é a pressuposição da existência de 'capital natural' para que possa existir capital produzido pelo ser humano, enquanto que a existência de 'capital natural' não pressupõe a existência de capital produzido pelo ser humano. 
Mas pouco intercede a favor da complementaridade, pois mesmo que haja uma pequena necessidade de 'capital natural' para uma larga produção de capital humano, a substituibilidade continuaria a ser a regra geral (Jamieson, 1998).

Daly (1995) coloca ainda que a relação da substituibilidade é, ou deve ser, simétrica. Isto é, ambos capitais são substituíveis um pelo outro. Argumentando pela complementaridade, Daly coloca que os ancestrais humanos não precisariam ter produzido quaisquer artefatos, em primeiro lugar. Mas, conforme aponta Holland (1997), nem sempre há um substituto disponível, tais ancestrais poderiam ter criado um artefato por não haver um equivalente no mundo natural, citando o clássico exemplo da roda, e mesmo que houvesse um equivalente natural não se pode inferir que os seres humanos não estariam dispostos ou aptos a produzir um equivalente, quer fossem levados pela necessidade, pela curiosidade ou pelo tédio. Ainda segundo Holland (1997), não se pode ignorar que mesmo levados pela necessidade a produzir um bem, este em si acaba criando novas necessidades - visto que as necessidades mudam com o evoluir das circunstâncias.

Jamieson (1998) aponta que o erro fundamental nessa suposição é de que a complementaridade e a substituibilidade não podem acontecer simultaneamente. Beckerman (1995) coloca que, em determinadas situações, os bens podem ser complementares e ao mesmo tempo substitutos, como acontece com a madeira e com o plástico. Mas, apesar da abordagem descritiva presente na sustentabilidade forte, $o$ ponto a ser reforçado deve ser o normativo. Ou seja, de que não se deve considerar o capital produzido pelo ser humano enquanto substituto para o capital natural, embora seja frequentemente considerado assim (Jamieson, 1998).

Ainda assim, a substituibilidade abordada pela sustentabilidade forte pode continuar nebulosa em certos aspectos. Já que seu intento é o de preservar o 'capital natural', parece que seria legítimo reduzir ou dizimar uma determinada espécie de uma região, desde que fosse ela preservada ou promovida em outra. Ora, o 'capital natural' continuaria a ser preservado, ou até mesmo aumentado. Já existem mecanismos e instrumentos econômicos, tais como os biodiversity offsets ${ }^{12}$, para operacionalizar essas compensações de biodiversidade. Os danos ambientais e ecológicos causados por um empreendimento podem ser compensados através dos biodiversity offsets. Existem offset banks, que são os 'lugares' nos quais são criados os projetos de compensações para se trocar por créditos de biodiversidade e consequentemente compensar os danos gerados (Bull et al., 2013). Funcionam de forma muito semelhante aos mecanismos de compensação de carbonos e equivalentes para mitigação ou redução dos impactos tardios das mudanças climáticas (Waeber, 2013).

Esses mecanismos e instrumentos econômicos tem se tornado uma grande tendência na conservação. No Brasil, tal se operacionaliza através das compensações de Reserva Legal, flexibilizado pelas alterações do Novo Código Florestal. O 'capital natural', antes uma metáfora econômica, uma abstração, tornou-se uma ideia chave em uma das principais instituições para a conservação da

\footnotetext{
${ }^{12} \mathrm{O}$ termo offset é frequentemente utilizado para denominar uma série de mecanismos e políticas, também conhecidos como criação compensatória de habitat (compensatory habitat creation), bancos de mitigação (mitigations banks), bancos de conservação (conservation banking), bancos de habitat (habitat banking), bancos de biodiversidade (biodiversity banking), entre outros.
} 
natureza e da biodiversidade no Brasil. Portanto, é de salientar que as políticas e regulamentações têm grande influência em como essas questões serão tratadas, mas a base conceptual importa sobremaneira para o estabelecimento dessas políticas.

Há, ainda, versões mais fortes da sustentabilidade, como a suportada pelo movimento da Ecologia Profunda, que tende a defender que outras espécies além da humana têm direito à vida, sendo únicas e insubstituíveis (van den Bergh, 2007). Uma implicação disso seria considerar ilegítimo dizimar uma espécie para que esta fosse promovida em outro lugar. Essas considerações nos remetem às discussões fundamentais da ética ambiental, que caberão em outras discussões (Beckert \& Varandas, 2004) que certamente influenciariam outras formas de sustentabilidade, talvez semelhantes à abordagem que será analisada a seguir.

Um relevante ponto crítico compartilhado por ambas as abordagens da sustentabilidade será revisto a seguir na sustentabilidade 'absurdamente forte'. Curiosamente, foi através de um posicionamento pejorativo de Daly (1995, p. 49) que o conceito começou a tomar forma, tendendo a negar a capitalização da natureza, revelando que o comprometimento da sustentabilidade deve ser com o mundo natural, não com o 'capital natural' (Holland, 1999).

\subsection{Sustentabilidade absurdamente forte}

A sustentabilidade forte afirma que há elementos naturais que não podem ser substituídos pelo capital humano. A sustentabilidade fraca admite a substituibilidade, desde que não seja reduzido o bem estar humano. Entretanto, ao aceitar que o declínio significativo dos elementos naturais compromete o bem estar humano, a substituibilidade não é determinista naquilo que difere as versões fraca e forte da sustentabilidade (Holland, 1997).

O debate sobre a sustentabilidade existe, sobretudo, em função do declínio da qualidade e quantidade do ambiente natural, ou visto por uma perspectiva econômica, os benefícios que a humanidade obtém do 'capital natural' estão em declínio. A problemática ambiental não se reduz ao contexto econômico, pelo que a economia será pouco capaz de oferecer a última resposta para a devastação do ambiente natural. A razão principal para a crise ambiental, como apontam Holland (1997) e outros autores (O’Neill, 1993; 1997; O’Neill, et al., 2008; ), não é o declínio do capital natural, mas o desaparecimento do mundo natural. O elevado crescimento populacional, o consumo exacerbado, as iniquidades de poder e a falta de discernimento ético-moral constituem, entre outras variáveis, as causas da supressão do ambiente natural.

A sustentabilidade forte difere da fraca, não determinantemente pela substituibilidade, mas especialmente pelas assunções e percepções básicas vislumbradas em cada qual. Se tiver em conta que os pressupostos da economia ambiental e da economia ecológica embebem as abordagens da sustentabilidade fraca e da sustentabilidade forte, respectivamente, as diferenças talvez fiquem mais evidenciadas.

A economia ecológica vem cumprindo um importante papel na tentativa de desvincular a problemática ambiental do viés neoclássico econômico. Contudo, permanece a obsessão em valorar e capitalizar a natureza. Ao admitir que a diferença entre as versões fraca e forte da sustentabilidade se apoia na maneira com que tratam o 'capital natural', 
seria inapropriado proclamar a sustentabilidade como uma meta para acabar com a crise ambiental. A teoria do 'capital natural' pode ser traiçoeira e ambas as abordagem de sustentabilidade podem ser colocadas em questão, ao invés de afirmadas, pelo debate da complementaridade e da substituibilidade, cujas diferenças - segundo Holland (1997) - tendem a ser exageradas.

Há suficientes incoerências no conceito de 'capital natural', conceber a natureza enquanto capital não oferece aceitável proteção para o mundo natural. O paradigma econômico tende a preservar a integridade de sua entidade, o capital, e na medida em a natureza é concebida como um capital, deixa ela de ser natureza (O’Neill, 1993; Holland, 1997). Cabe relembrar que o 'capital natural' é considerado em função dos interesses humanos e, portanto, mesmo que ele seja sustentado, o mundo natural poderá continuar a desaparecer, revelando desconsideração pela sua completude. Se a sustentabilidade forte não é capaz de assegurar a preservação da natureza, Holland (1999) afirma que este é um papel para a sustentabilidade 'absurdamente forte' ( 'absurdly strong' sustainability). Holand (1999) declara que a sustentabilidade 'absurdamente forte' alega que a natureza não deve ser substituída, mesmo quando houvesse possibilidades de ser.

Daly (1995) define a sustentabilidade 'absurdamente forte' - pejorativamente - em resposta a um argumento de Beckerman (1995), como uma vertente em que nenhuma espécie poderia vir a extinguir-se, e nenhum 'recurso' não renovável poderia ser utilizado, não importando quão famintas estivessem as pessoas ${ }^{13}$. Beckerman (1994, p. 194), anteriormente argumentou que um dos requisitos para a conservação seria "[...] preservar intacto o ambiente como o encontramos hoje em todas as suas formas [...]". Daly (1995) interpretou de forma bastante literal a conservação vislumbrada por Beckerman, como vimos acima. Sendo assim, uma representação absurda da sustentabilidade.

A defesa de Holland (1997) é que, se pretendemos esboçar uma versão forte da sustentabilidade, ela deve revelar um comprometimento com o mundo natural, o que as sustentabilidades fraca e forte não evidenciaram de forma consistente. Não se pretende conservar o ambiente natural através de parâmetros estáticos, se assim talvez fosse mais nocivo que benéfico, pois sabe-se que os sistemas naturais - bem como os humanos - são dinâmicos e dependem dessa dinamicidade e elasticidade. A conservação e preservação do ambiente natural devem pressupor isto minimamente em qualquer forma de sustentabilidade. Obviamente não se pretende que as pessoas padeçam de fome pela conservação da natureza, mas que esta seja preservada para além dos interesses humanos. Isto sim é o que Holland (1997) argumenta ser um ideal da sustentabilidade absurdamente forte - se, afinal, isto for absurdo.

A sustentabilidade é frequentemente encarada enquanto norma (Newton, 2003; Norton, 2005; Becker, 2011), mas não é um bem em si mesmo,

\footnotetext{
13 “Beckerman's concept of strong sustainability, however, is one made up by himself in order to serve as a straw man. In the literature, weak sustainability assumes that manmade and natural capital are basically substitutes. He got that right. Strong sustainability assumes that manmade and natural capital are basically complements. Beckerman completely missed that one. He thinks strong sustainability means that no species could ever go extinct, nor any nonrenewable resource should ever be taken from the ground, no matter how many people are starving. I have referred to that concept as 'absurdly strong sustainability' in order to dismiss it, so as to focus on the relevant issue: namely, are manmade and natural capital substitutes or complements? That is really what is at issue between strong and weak sustainability" (Daly, 1995, p. 49).
} 
e segundo Jacobs (1995) não deve ser a única a guiar os princípios, sobrepujando outras considerações morais. No entanto, não deve-se afirmar que qualquer prática que pode ser julgada hostil aos interesses humanos, seja imoral (Holland, 1997). Isto significa dizer que os interesses humanos são relativos, não absolutos.

É relevante frisar que o mundo está cada vez mais ameaçado por danos causados pela humanidade. Poluições multifacetadas, perda de biodiversidade, secas e desertificação, entre outras tantas mazelas, e o fenômeno das alterações climáticas tende a aumentar ainda mais tais danos, bem como as iniquidades entre os humanos. Grande parte das gerações presentes está se apropriando de enormes quantidades das fontes naturais, o que revela a forte injustiça e iniquidade em relação às gerações humanas futuras, bem como às presentes e futuras gerações de entidades não-humanas.

De fato a economia pode, através da mensuração, fornecer certas informações que poderão ser úteis em devidas circunstâncias, mas não é a valoração econômica o sustentáculo para colocar a humanidade no caminho correto (Holland, 1997). Não apenas pela imprecisão da valoração, mas pelas assunções e percepções básicas da razão, das instituições e da moralidade que sustentam a prática econômica atual.

\section{Considerações finais}

Buscou-se, com este trabalho, demonstrar que o vislumbre da natureza estritamente pelo viés da economia moderna e suas variações (economia neoclássica, economia ambiental, economia ecológica) influencia enormemente as concepções e abordagens da sustentabilidade. Ao reconhecer a sustentabilidade enquanto processo fundamental para o trilhar da humanidade, perspectivando o equilíbrio com a natureza, não se deve passar por seus aspectos conceptuais despercebidamente, faz-se imprescindível uma reflexão mais sensível.

A sustentabilidade não se reduz ao seu viés econômico, ela atravessa sistemas globais diversos que atuam sobre as sociedades, regendo-as e sendo regidos por elas através de uma complexa rede de interações. Sendo assim, os padrões de pensamento e ação, bem como as instituições que conduzem as dinâmicas relacionais das sociedades são, em grande medida, condicionados pelas importantes estruturas globais, como a ciência, a tecnologia, a política, a educação e, dentre outras, a economia.

As relações humanas são assimétricas, complexas em suas especificidades. As pessoas relacionam-se umas com as outras através do globo por processos que elas mesmas tendem a desconhecer, desde o alimento produzido aos aparelhos eletrônicos descartados (Becker, 2010). A sustentabilidade atua nos níveis individual, social e global, que atravessam gerações humanas e não-humanas, corroborando a necessidade de ser abordada de modo mais abrangente, demandando apreciação ética.

É nesse ponto que Holland (2003) assinala que uma nova ética pode ser um dos ingredientes para um novo entendimento sobre o desenvolvimento, tal como Leff (2004) também reflete sobre a necessidade de uma nova racionalidade. A finalidade da economia, assim como da sustentabilidade, não deve ser o crescimento pelo crescimento. No final dos anos 1960, Daly (1968) rebuscou a ideia da necessidade de um estado estacionário para a economia (steady state economy). Curiosamente, no seio do utilitarismo, uma espécie de estado es- 
tacionário já fora vislumbrado por John Stuart Mill quando este coloca que é necessária uma condição estacionária do capital sem que haja estagnação no aprimoramento humano cultural, moral e social ${ }^{14}$. Fica implícito que Mill (1909[1848]) não idealizou apenas um futuro ideal através da utilidade e dos interesses pessoais egoístas, como usualmente se pensa o utilitarismo, mas vislumbrou a importância de um futuro que aporte o progresso cultural, social e moral criando oportunidades para aprimorar a "Arte de Viver" (Art of Living).

Jackson (2009) fala em 'prosperidade sem crescimento' como uma necessidade para a humanidade. $\mathrm{O}$ conceito de decrescimento (do francês décroissance), por exemplo, vai ainda mais longe ao argumentar que uma estado estacionário não é suficiente, sendo necessária uma redução no metabolismo social (Kallis, 2011) e ampara a afirmação de que o desgaste social advindo da trajetória econômica reducionista prepara um futuro arriscado, perigoso e mesmo amoral, imbuído de injustiças (sociais, ambientais e ecológicas), o que invariavelmente trará danos para a natureza e também para os seus filhos presunçosamente desgarrados, os humanos (Latouche, 2011). Requer-se um caminho que aproxime a ética da economia, que possa ser vislumbrado pela sustentabilidade. Contudo, a ideia de uma nova economia, isto é, de um novo entendimento da economia na relação humana, re- quer uma outra lógica para o sistema que não seja a idolatria do desenvolvimento caracterizado por um crescimento pelo crescimento (Latouche, 2011).

O pensamento econômico passou a tratar dos limites ecológicos e ambientais e o fez de formas diversas, tanto perspectivado pela economia ecológica quanto pela ambiental. Contudo, foi o pensamento economicista ${ }^{15}$ que abraçou as questões sobre como os valores ambientais podem articular as escolhas de políticas públicas. Não obstante, foi a influência da corrente tradicional neoclássica que acabou por guiar as práticas valorativas da chamada 'economia verde' (Foster, 1997). É verdade que a economia se tornou mais sensível, mas assim também cresceu a dominância do economicismo sobre a meta-economia pensando nos aspectos humanos vitais e em suas relações com o mundo natural não-humano (Foster, 1997).

As metáforas econômicas, (como 'capital natural' e 'serviços ecossistêmicos') lançam outro olhar sobre a natureza, aportando discursos e arranjos institucionais que, aliados a dispositivos técnico-econômicos, postulam valores econômicos para pessoas e outras entidades. Os excessos da valoração econômica levam-nos a demarcar unidades monetárias para a Natureza, identificando-a como uma mercadoria. A mercadoria tem não só um valor de uso, mas ao mesmo tempo um valor de troca associado. Nesse sentido, a valorização econômica

\footnotetext{
14 "It is scarcely necessary to remark that a stationary condition of capital and population implies no stationary state of human improvement. There would be as much scope as ever for all kinds of mental culture, and moral and social progress; as much room for improving the Art of Living [...]" (Mill, 1909[1848], p. 69).

${ }^{15} \mathrm{O}$ pensamento economicista envolve o pensar de maneira estritamente econômica, centrado exclusivamente nas questões de produção e consumo, no qual é fundamental o cálculo econômico e, no que concerne à natureza, deve ser tratada como um bem para ser considerado neste cálculo. O pensamento economicista também pode tentar considerar outros elementos (não econômicos). Contudo, para tal, não reconhece um limite para o seu delineamento, trazendo a natureza para consideração sob uma abordagem econômica. Por exemplo, os elementos naturais passam a ser abordados enquanto capital e serviços para serem considerados no âmbito econômico (Schumacher, 1973; Foster, 1997).
} 
da natureza, especialmente em termos monetários, habilita sua transação tal como uma mercadoria qualquer, evidenciando um caráter de fetichismo de mercadoria (Marx, 1867). O valor econômico da natureza também poderá influenciar sua percepção na lógica de mercado, lançando-a na dinâmica da oferta e demanda e concebendo as dificuldades em torno dos conflitos ambientais como externalidades negativas. As metáforas econômicas da natureza consolidam sua caracterização enquanto bem (capital natural) e serviço (serviços ecossistêmicos) econômicos. Todo esse percurso da valorização da natureza não acontece isoladamente, mas está inserido em um projeto mais amplo, o neoliberalismo, sendo este um poderoso projeto político ideológico que influencia todo o trajeto global político, cultural e econômico, implicando igualmente na forma como o ser humano endereça suas relações com o mundo natural e seus valores constituintes.

A racionalidade econômica, como Leff (2004) coloca, utiliza de uma métrica que reduz a diversidade ontológica e axiológica do mundo a valores uniformes, quantitativos e objetivos que favorecem disseminação e incorporação do mercado nas esferas da sociedade. A sustentabilidade 'absurdamente forte' apela a uma nova racionalidade capaz de reconhecer uma pluralidade de valores sintonizada com as possibilidades da sustentabilidade que transcendem suas versões forte e fraca, já tão influenciadas pela economia dominante.

Para seguirmos além do valor econômico, é requerido repensar o papel da economia e redirecioná-la através da meta-economia (Schumacher, $1973)^{16}$. Isto é, através daquele pensamento econô- mico que atribui nossa forma de pensar, decidir e agir. Confrontar a racionalidade econômica significa reconhecer e oportunizar uma nova razão, tal como defende Leff (2004), uma racionalidade ambiental, que emerge do questionamento da sobre-economização do mundo, construindo novos modos de vida que rearticulam as relações entre cultura e natureza. Requer-nos reavaliar quais valores devem reger a economia, quais valores reconhecer ao integrar o debate da degradação natural nas nossas escolhas sociais e econômicas, como colocam Spash \& Aslaksen (2015), a transformação necessária rumo à sustentabilidade envolve respeitar a riqueza das relações humanas com a natureza. Do mesmo modo, Illich (1975) argumenta que o equilíbrio ecológico depende da capacidade das estruturas sociais de contrapor a contínua materialização dos valores, isto é, confrontar a apropriação técnico-econômica dos diversos aspectos da vida.

Decisões complexas precisam ser tomadas e são infindas as variáveis sociais, culturais, ambientais, materiais e morais que recaem sobre tais decisões. Contudo, não deveria ser a unidade monetária, orientada por critérios arbitrários (típicos da economia neoclássica), a derradeira orientadora das decisões humanas. O que se deve aplicar é um apropriado julgamento prático, a faculdade de discernir entre os valores que estão em jogo. $\mathrm{O}$ valor monetário talvez possa assistir a sabedoria e o julgamento práticos, mas não substituí-los (O'Neill, 1997). A sustentabilidade tornou-se um conceito fundamental, apesar das discordâncias quanto ao seu entendimento. Entretanto, uma sustentabilidade genuína deve fazer referência não apenas ao desen-

\footnotetext{
${ }^{16}$ Schumacher introduziu em 1973 uma distinção entre economia e o que ele chamava de meta-economia: uma distinção entre os processos econômicos e o que atribui o contexto desses processos, respectivamente.
} 
volvimento econômico, mas ao desenvolvimento humano que seja compatível com suas intenções, com aquilo que a humanidade julga apropriado para sua convivência, não tão somente consigo mesma, mas com as demais manifestações da vida no Planeta (Muniz, 2013).

As considerações morais e econômicas podem levar a diferentes direções. A própria sensibilidade moral leva a caminhos distintos (Holland, 1999). Não obstante, é preciso que seja enfatizado que:

[...] de um lado, a 'crise' - o ritmo e a extensão com que se dá a perda do mundo natural - não é (apenas) uma crise econômica e, por outro, a perda da ' $[\mathrm{N}]$ atureza' não é (apenas) a perda de um ideal romântico, mas a perda da nossa própria história e da comunidade da vida da qual pertencemos (Holland, 1999, p. 133).

\section{Agradecimentos}

O autor agradece pelas contribuições dos avaliadores anônimos.

\section{Referências}

Barkin, D.; Carrasco, M. E. F.; Zamora, D. T. La significación de una Economía Ecológica radical. Revista Iberoamericana de Economía Ecológica, 19, 1-14, 2012.

Baumgärtner, S.; Becker, C.; Faber, M.; Manstetten, R. Relative and Absolute Scarcity of Nature. Assessing the Roles of Ecology and Economics for Biodiversity Conservation. Ecological Economics, 59, 487-498, 2006.

Baxter, B. A Theory of Ecological Justice. London: Routledge, 2005.

Becker, C. U. The human actor in ecological economics:
Philosophical approach and research perspectives. Ecological Economics, 60(1), 17-23, 2006.

Becker, C. U. Sustainability Ethics Sustainability Ethics. v. 1, n. 814, p. 1-15, 2010.

Becker, C. U. Sustainability Ethics and Sustainability Research. Dordrecht: Springer Netherlands, 2011.

Beckerman, W. Sustainable development: is it a useful concept? Environmental Values, 3, 191-209, 1994.

Beckerman, W. How Would You Like Your Sustainability, Sir? Weak Or Strong? Environmental Values, 4, 169-179, 1995.

Beckert, C.; Varandas, M. J. Éticas e políticas ambientais. Lisboa: Centro de Filosofia da Universidade de Lisboa, 2004.

Beder, S. Environmental economics and ecological economics: the contribution of interdisciplinarity to understanding, influence and effectiveness. Environmental Conservation, 38(2), 140-150, 2011.

Berkes, F.; Folke, C. Investing in cultural capital for sustainable use of natural capital. In: Jansson, A.; Hammer, M.; Folke, C.; Costanza, R. (Eds.). Investing in Natural Capital. Washington: Island Press, 1994. p. 128-149.

Bina, O.; Vaz, S. G. Humans, environment and economies: From vicious relationships to virtuous responsibility. Ecological Economics, 72, 170-178, 2011.

Bull, J. W.; Suttle, K. B.; Gordon, A.; Singh, N. J.; Milner-Gulland, E. J. Biodiversity offsets in theory and practice. Oryx, 47(3), 369-380, 2013.

Costanza, R. Reintegrating the Study of Humans and Nature. Ecological Applications, 6(4), 978-990, 1996.

Daly, H. On economics as a life science. Journal of Political Economy, 76, 392-406, 1968.

Daly, H. Allocation, distribution and scale: towards an economics that is efficient, just and sustainable. Ecological Economics, 6, 185-193, 1992.

Daly, H. On Wilfred Beckerman's critique of sustainable development. Environmental Values, 4(1), 49-55, 1995.

Dower, N. The ethics of sustainability. In: Mather, A.; Bry- 
den, J. (Eds.). Regional of sustainable development: Europe. Oxford: Eolss Publishers, 2003. p. 277-298.

Ehrenfeld, D. Why put a value on Biodiversity? In: Wilson, E. O.; Frances, P. M. (Eds.). Biodiversity. Washington: National Academy Press, 1988, p. 212-216.

Fernandes, V. A racionalização da vida como processo histórico: crítica à racionalidade econômica e ao industrialismo. Cadernos EBAPE, 6(3), 2008.

Fernandez, B. P. M. Ecodesenvolvimento, Desenvolvimento Sustentável e Economia Ecológica: em que sentido representam alternativas ao paradigma de desenvolvimento tradicional? Desenvolvimento e Meio Ambiente, 23, 109-120, 2011.

Foladori, G.; Tommasino, H. El concepto de desarrollo sustentable treinta años después. Desenvolvimento e Meio Ambiente, 1, 41-56, 2000.

Foster, J. Introduction: Environmental value and the scope of economics. In: Foster, J. (Ed.). Valuing nature? Ethics, economics and the environment. London: Routledge, 1997. p. 1-20.

Georgescu-Roegen, N. The entropy law and the economic process. Cambridge: Harvard University Press, 1971.

Gómez-Baggethun, E.; Groot, R.; Lomas, P. L.; Montes, C. The history of ecosystem services in economic theory and practice: From early notions to markets and payment schemes. Ecological Economics, 69(6), 1209-1218, 2010.

Gorz, A. Critique of economic reason. London: Verso, 1989.

Holland, A. Substitutability: or, why strong sustainability is weak and absurdly strong sustainability is not absurd. In: Foster, J. (Ed.). Valuing nature? Ethics, economics and the environment. London: Routledge, 1997. p. 119-135.

Holland, A. Sustainability: Should We Start From Here? In: Dobson, A. (Ed.). Fairness and Futurity: Essays on Environmental Sustainability and Social Justice. Oxford: Oxford University Press, 1999. p. 46-68.

Holland, A. Sustentabilidade. In: Jamieson, D. (Ed.). Manual de Filosofia do Ambiente. Lisboa: Instituto Piaget, 2003. p. 401-413.

Illich, I. Tools for conviviality. Glasgow: Fontana/Collins, 1975.
Jackson, T. Prosperity without growth. Economics for a finite Planet. Stearling: Earthscan, 2009.

Jacobs, M. Sustainable development, capital substitution and economic humility: a response to Beckerman'. Environmental Values, 4, 57-68, 1995

Jamieson, D. Sustainability and beyond. Ecological Economics, 24, 183-192, 1998.

Kallis, G. In defence of degrowth. Ecological Economics, 70(5), 873-880, 2011.

Latouche, S. O Pequeno Tratado do Decrescimento Sereno. Lisboa: Edições 70, 2011.

Leff, E. Racionalidad ambiental. La reapropriación social de la naturaleza. México: Siglo XXI Editores, 2004.

Marx, K. Capital, Volume One, Part One: Commodities and Money, 1867. Disponível em: <https://www.marxists.org/ archive/marx/works/1867-c1/ch01.htm> Acesso dez. 2014

Meadows, D. H.; Meadows, D. L.; Behrens III. W. W. J. R. The Limits to Growth. New York: Universe Books, 1972.

Mill, J. S. Principles of Political Economy. with some of their Applications to Social Philosophy [Of the Stationary State, Book IV, Chapter VI]. London: William J. Ashley Ed. Library of Economics and Liberty. 1909 [1846]. Disponível em: <http://www.econlib.org/library/Mill/mlP61.html> Acesso em jun. 2012.

Muniz, R. Caminhos para a sustentabilidade: alterações climáticas e sociedades em transição. Boletim de Geografia, 31(2), 5-18, 2013.

Murtaza, N. Pursuing self-interest or self-actualization? From capitalism to a steady-state, wisdow economy. Ecological Economics, 70, 577-584, 2010.

Newton, L. Ethics and Sustainability: Sustainable Development and Moral Life. Upper Sadle River: Prentice Hall, 2003.

Norton, B. G. Sustainability: A New Philosophy of Adaptive Ecosystem Management. Chicago: University of Chicago Press, 2005.

O’Neill, J. Ecology, Policy and Politics: Human Well-Being and the Natural World. London: Routledge, 1993.

O’Neill, J. Value Pluralism, Incommensurability and Institu- 
tions. In: Foster, J. (Ed.). Valuing nature? Ethics, economics and the environment. London: Routledge, 1997. p. 75-89.

O’Neill, J.; Holland, A.; Light, A. Environmental Values. London: Routledge, 2008.

Pearce, D.; Markandya, A.; Barbier, E. Blueprint for a Green Economy. London: Earthscan, 1989.

Pearce, D. The precautionary principle and economic analysis. In: O'riordan, T.; Cameron, J. (Eds.). Interpreting the Precautionary Principle. London: Earthscan, 1994. p. 132-151.

Pearce, D. An intellectual history of environmental economics. Annual Review of Energy and the Environment, 27, 57-81, 2002.

Polanyi, K. The great transformation. The political and economic origins of our time. Boston: Beacon Press, 1957.

Redclift, M. Sustainable Development: Exploring the Contradictions. London: Routledge, 1987.

Robbins, L. An Essay on the Nature and Significance of Economic Science. London: Macmillan, 1932.

Sachs, I. Estratégias de transição para o século XXI: desenvolvimento e meio ambiente. São Paulo: Studio Nobel/ Fundap, 1993.

Schumacher, E. F. Small is Beautiful: Economics as if People mattered. London: Vintage, 1973.

Shiva, V. Recovering the Real Meaning of Sustainability. In: Cooper, D.; Palmer, J. A. (Eds.). The Environment in Question: Ethics and Global Issues. London: Routledge, 1992. p. 187-193.
Simpson, J.; Weiner, E. The Oxford English Dictionary. Second ed. Oxford: Oxford University Press, 1989.

Solow, R. Intergenerational equity and exhaustible resources. Review of Economic Studies, 42, 29-45, 1974.

Soromenho-Marques, V. O Futuro Frágil. Os desafios da crise global do ambiente. Mem Martins: Europa-América, 1998.

Spash, C. L. The Development of environmental thinking in economics. Environmental Values, 8, 413-435, 1999.

Spash, C. L.; Aslaksen, I. Re-establishing an ecological discourse in the policy debate over how to value ecosystems and biodiversity. Journal of Environmental Management, 159, 245-253, 2015.

Tietenberg, T. Environmental And Natural Resource Economics. Third ed. New York: Harper Collins Publishers, 1992.

van den Bergh, J. C. J. M. Themes, Approachs, and Differences with Environmental Economics. Discussion Paper, Tinbergen Institute. 2000. Disponível em: <http://www. tinbergen.nl/uvatin/00080.pdf> Acesso em: ago. 2012

van den Bergh, J. C. J. M. Sustainable development in ecological economics. In: Atkinson, G.; Dietz, S.; Neumayer, E. (Eds.). Handbook of Sustainable Development. Cheltenham: Edward Elgar Publishing Limited, 2007. p. 63-78.

Waeber, P. O. Biodiversity offsetting - en vogue in Madagascar? Madagascar Conservation \& Development, 7(3), 110-111, 2013.

WCED - World Commission On Environment And Development. Our Common Future. Oxford: Oxford University Press, 1987. 